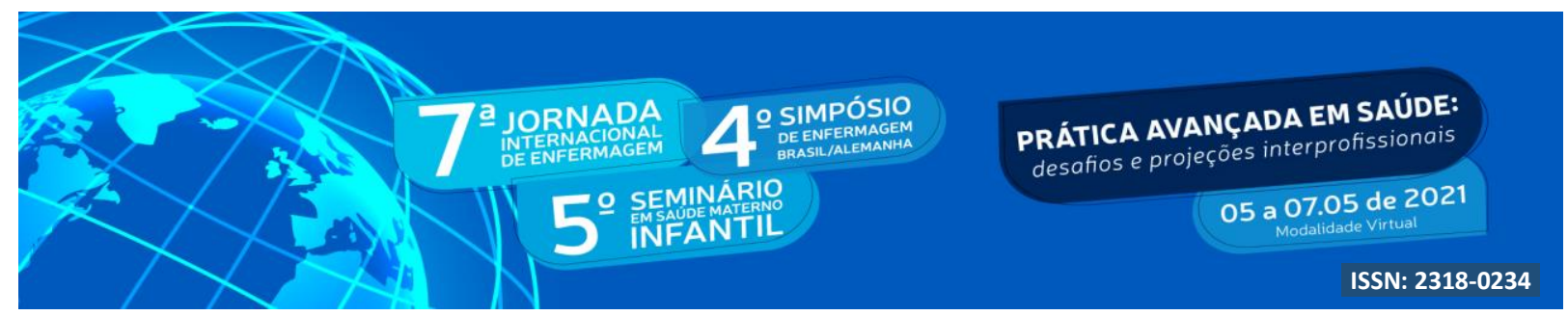

DOI: http://doi.org/10.48195/jie2021-168

\title{
ENFRENTAMENTO DA PANDEMIA DA COVID-19 EM UM CENTRO OBSTÉTRICO: RELATO DE EXPERIÊNCIA ${ }^{1}$
}

\author{
Julieli Rosso $^{2}$; Caroline Ilha ${ }^{3}$; Amanda Comassetto ${ }^{4}$
}

\begin{abstract}
RESUMO
Este relato de experiência teve o objetivo de relatar as ações da equipe de enfermagem no enfrentamento a pandemia do novo coronavírus em um Centro Obstétrico no interior do Rio Grande do Sul. A pandemia Covid-19 que emergiu no final de 2019 em Wuhan, na China, se disseminou por todos os continentes. Trata-se de um relato de experiência de uma enfermeira assistencial. Vários fluxos de atendimento foram adaptados. Das pacientes positivas para Covid 19 para a grande maioria, foi indicado o parto cesáreo. Quando a internação é para resolução da gestação, nota-se um misto de sentimentos, visto que é uma grande alegria a chegada de um novo membro na família, mas em um momento de muitas dúvidas e acontecimentos em todo o mundo. Devido a pandemia o Centro Obstétrico tem passado por muitos momentos de tensão e preocupação, pois todos os dias há pessoas do convívio e da equipe com resultado positivo para a Covid19.
\end{abstract}

Palavras-chave: Coronavírus, Pandemia, Covid-19.

\begin{abstract}
This experience report had the objective of reporting the actions of the nursing team in confronting the pandemic of the new coronavirus in an Obstetric Center in the interior of Rio Grande do Sul. The Covid-19 pandemic that emerged in late 2019 in Wuhan, China, has spread to all continents. It is an account of the experience of an assisting nurse. Several service flows have been adapted. Of the patients positive for Covid 19 for the vast majority, cesarean delivery was indicated. When hospitalization is for the resolution of pregnancy, mixed feelings are noted, as it is a great joy to have a new member in the family, but at a time of many doubts and events around the world. Due to the pandemic, the Obstetric Center has gone through many moments of tension and concern, because every day there are people from the community and from the team with a positive result for Covid19.
\end{abstract}

Key Words: Coronavirus, Pandemic, Covid-19.

\footnotetext{
${ }^{1}$ Artigo completo: relato de experiência

${ }^{2}$ Enfermeira Assistencial e Estudante do Curso de Pós-Graduação Materno-Infantil. UFN. Email: julielirosso@yahoo.com.br

${ }^{3}$ Enfermeira e Estudante de Doutorado UFSM- Múrcia. E-mail: carol.bilha@gmail.com

${ }^{4}$ Estudante de Enfermagem. FISMA. E-mail: comassettoamanda@gmail.com
} 


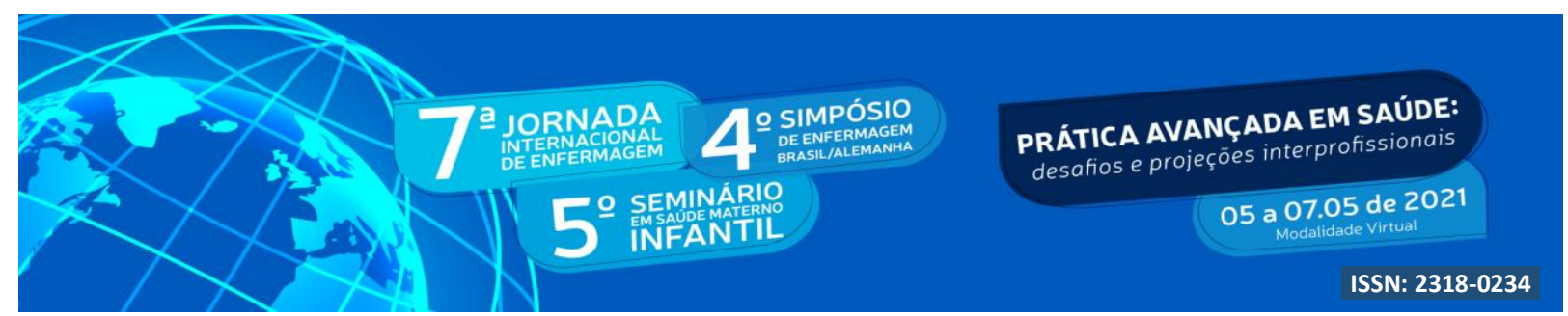

\section{INTRODUÇÃO}

Periodicamente, no mundo ocorrem eventos naturais de pandemias virais, como as que ocorreram no século passado em 1918, 1957 e 1968, com índices elevados de letalidade, a exemplo da gripe espanhola e aviária. Em 2009 no México foi identificado o vírus da Influenza A (H1N1), o qual se disseminou de forma rápida, provocando considerável desordem nos sistemas de saúde em virtude do grande número de casos e de óbitos em várias partes do mundo, inclusive no Brasil.

A pandemia Covid-19, causada pelo SARS-CoV-2, que emergiu no final de 2019 em Wuhan, província de Hubei, na China, se disseminou por todos os continentes, aumentando exponencialmente o número de infectados e ocasionando milhares de mortes no mundo (Zhu et al. 2020). Trata-se de um novo Coronavírus, da ordem Nidovirales, família Coronaviridae, subfamília Orthocoronavirinae. Foi nomeado síndrome respiratória aguda grave coronavírus-2 ou SARS-CoV-2 pelo Comitê Internacional de Taxonomia de Vírus e a Organização Mundial da Saúde (OMS) declarou a Covid -19 como nome dessa nova doença, em fevereiro de 2020.

Em dezembro de 2019 e janeiro de 2020, foram identificados casos de pneumonia atípica em Wuhan, na China. Nos pacientes afetados, a reação em cadeia da polimerase em tempo real conhecido como exame RT-PCR do lavado bronco alveolar foi negativa para a conhecida SARS-CoV. Por outro lado, o vírus encontrado nessas amostras foi submetido a análises filogenéticas e de recombinação, que revelaram semelhança de 99,9\% com a família Coronavírus.

Acredita-se que os primeiros casos de Covid -19 tenham sido associados a um mercado de frutos do mar em Wuhan, onde pacientes contaminados costumavam consumir

alimentos. Supõe-se ainda que o mecanismo de infecção tenha passado de animal para humano. No entanto, o surgimento de outros casos foi decorrente de interações humanas e essa transmissão pode ocorrer antes do início dos sintomas da doença por indivíduos assintomáticos. Após a detecção desse novo agente etiológico, chamado Covid 19/2019nCoV, o número de indivíduos contaminados na China cresceu exponencialmente, 


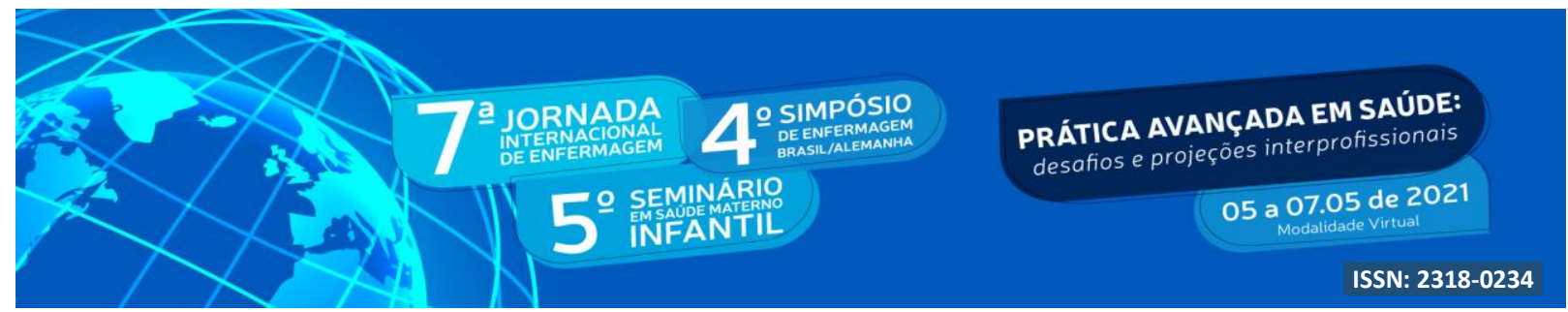

tomando grande proporção em outros países. A doença foi considerada pela OMS como pandemia em março de 2020.

Segundo o Boletim Epidemiológico $n^{\circ} 5$ do Ministério da Saúde, no Brasil, o primeiro caso foi confirmado na cidade de São Paulo, em 26 de fevereiro de 2020 e estava associado a pacientes que chegavam de países como a Itália que já sofria explosão de casos e mortes com a doença. A Covid19 se espalhou por todo o país, atingindo mais de 12,4 milhões de casos notificados e 318 mil mortes relacionadas em 30 de março de 2021. Um mês após o primeiro caso confirmado no Brasil, no dia 26 de março de 2020, foi declarada transmissão comunitária em todo o território nacional, isto é, não mais rastreável como os primeiros casos (OPAS, 2020). No dia 21 de março foi confirmado o primeiro paciente com Covid19 em Santa Maria e desde então foram confirmados 14.172 casos e 400 óbitos de acordo com o Observatório de Informações em Saúde da UFSM.

Destarte, a infecção com SARS-CoV-2 se apresentou clinicamente com uma destas três principais condições: portadores assintomáticos, indivíduos com doença respiratória aguda (DRA) ou pacientes com pneumonia em diferentes graus de gravidade.

Alguns sintomas iniciais se assemelham aos de outras infecções respiratórias virais, como Norovirose e Influenza. Dispneia e febre alta são sintomas que definem a principal diferença clínica entre a COVID-19 e o resfriado comum, que é acompanhado de congestão nasal, lacrimejamento, espirros e coriza, inicialmente hialina, mas que ao longo dos dias se torna amarelo-esverdeada. Por outro lado, quando comparada com a infecção por Influenza, a COVID-19 apresenta sintomas clínicos semelhantes, mas com maior proporção de evoluções para infecções graves e críticas, por vezes exigindo oxigenoterapia e suporte ventilatório (WHO, BRASIL, 2020).

Embora menos descrita nos casos relatados, a perda de olfato e paladar não acompanhada de coriza ou congestão nasal ganhou destaque ao longo do ano de 2020 persistindo nos casos de 2021, fato que aumenta a possibilidade de comprometimento neurológico direto pela SARS-CoV-2, embora sejam necessários mais estudos para tal afirmação (MAO et. al.; 2020).

Entre os grupos de risco adicionados recentemente na lista para complicações pela COVID-19 no Brasil estão as gestantes em qualquer idade gestacional e puérperas até duas 


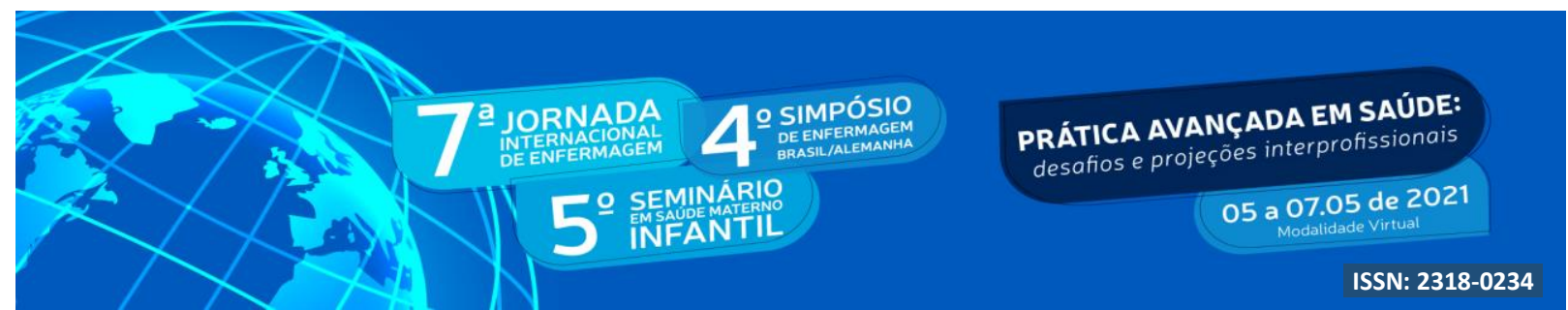

semanas após o parto, incluindo as que tiveram aborto ou perda fetal (BRASIL, 2020). Tal grupo foi incluído no país devido à incidência de casos e o aumento crescente do número de mortes entre a população gestantes e puérperas, em comparação com outros países do mundo (AMORIM, TAKEMOTO, FONSECA, 2020). Principalmente nos países em desenvolvimento, as razões de morte materna, neste período de pandemia, mostraram-se aumentadas (HANTOUSHZADEH et. al. 2020).

\section{OBJETIVO}

Relatar as ações da equipe de enfermagem no enfrentamento a pandemia do novo coronavírus em um Centro Obstétrico (CO).

\section{METODOLOGIA}

Trata-se de um relato de experiência o qual descreve as observações de uma enfermeira assistencial em um Centro Obstétrico em um Hospital Universitário do interior do Rio Grande do Sul. As observações em questão ocorreram a partir do primeiro caso confirmado do novo coronavírus no Brasil, sendo o dia 21 de março de 2020 até o primeiro trimestre de 2021, totalizando um ano de observações. O público alvo das observações foram as gestantes atendidas no referido $\mathrm{CO}$.

\section{RESULTADOS E DISCUSSÃO}

As observações desse relato de experiência são relacionadas principalmente os efeitos diretos ou indiretos da pandemia COVID-19 no Centro Obstétrico.

Destarte, foram oferecidos cursos e capacitações com o objetivo de atualizar os protocolos usados no enfrentamento da Covid19 no Centro Obstétrico e no Hospital. Num primeiro momento as capacitações foram presenciais, mas em função do aumento de casos, as atualizações passaram a ocorrer no formato EAD, para fins de evitar aglomerações.

A princípio foram orientadas mudanças nos fluxos de pessoas e criou-se no $\mathrm{CO}$ o isolamento Covid, sendo esta área chamada de CO Covid e o restante da unidade como CO não Covid, o CO Covid contava com dois leitos, em ambientes separados, sendo um equipado com berço aquecido para parto sem intervenção e pós parto. 


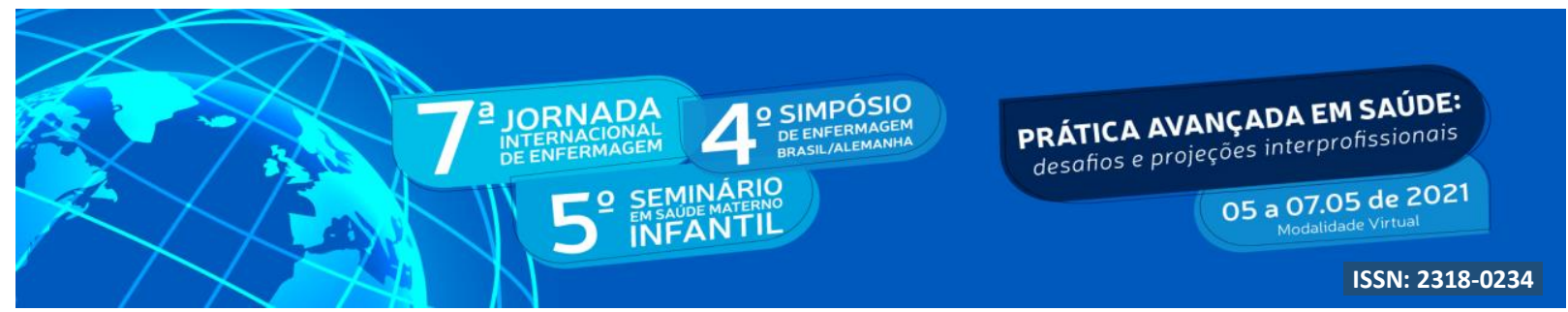

Vários fluxos de atendimento foram adaptados, para que nenhuma paciente suspeita ou já positiva para Covid-19, chegasse na área não Covid do CO. Já na entrada da paciente, na recepção da portaria do Pronto Socorro (PS), onde é feito o cadastro e aberto ficha, a mesma passava por uma triagem rápida pela equipe de enfermagem do PS, sendo a paciente suspeita, a mesma é direcionada à um consultório, que foi disponibilizado e montado para estas pacientes serem avaliadas de forma segura.

A funcionária da portaria comunica o $\mathrm{CO}$ e uma residente da medicina vai até o consultório para avaliar a paciente. Porém não pôde ser mantido dessa forma, devido à dificuldade de disponibilizar funcionários. Diversas vezes aconteceu de paciente suspeita chegar na área não Covid do $\mathrm{CO}$, por essa triagem falhar, sendo necessário realizar desinfecção em toda área em que a paciente esteve. Hoje a triagem não é feita, porém foi criado um checklist de sinais e sintomas que é entregue para a gestante e se ela não apresenta nenhum dos sintomas, passa para o CO não Covid. Se tiver um dos sintomas, a mesma será orientada a aguardar consulta no consultório que foi destinado para esse fim.

Observou-se na literatura que em geral, as gestantes com Covid-19, não parecem apresentar sintomas mais graves da doença do que as não gestantes. De início a maioria dos casos entre grávidas foi assintomática ou levemente sintomática (DELAHOY, 2020).

Por alguns meses houveram os testes rápidos disponíveis na unidade, sendo testadas todas as pacientes que internavam, o teste era realizado pela enfermeira, juntamente com os testes de HIV e de sífilis. Porém os testes rápidos da Covid, ficaram escassos e passaram a ser realizados somente pelo laboratório, conforme liberação do Controle de Infecções Hospitalares (CCIH).

As escalas de serviço foram organizadas de forma a contemplar a área Covid, sendo escaladas, sempre uma técnica e uma enfermeira, essas são deslocadas da área CO não Covid, ficando a equipe reduzida nos dias que possui paciente no CO Covid.

Com a evolução da pandemia ao longo do ano, algumas cirurgias eletivas voltaram a ser realizadas necessitando da entrega de uma das salas de isolamento que ficou sem uso por um tempo. Precisando assim ser reorganizado novamente o CO Covid, ficando apenas uma sala ampla para parto e pós parto e passou-se a usar uma peça pequena para pacientes em observação ou com menos necessidade de intervenção. 


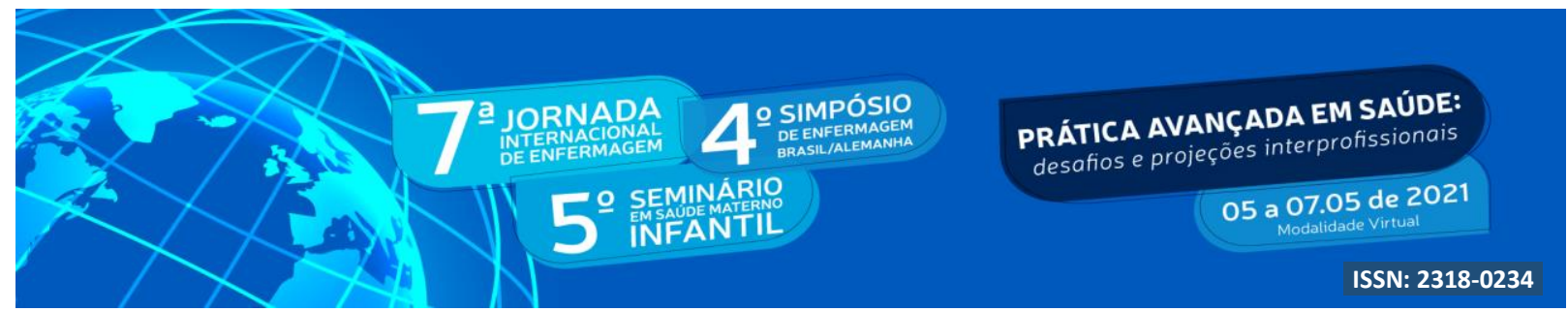

Com o aumento da demanda e explosão de casos Covid, em alguns momentos foi necessário isolar os casos suspeitos no CO não Covid, fazer testagem e esperar os resultados. Nesse sentido, gerou-se estresse na equipe por dúvidas quanto à exposição frente a pacientes contaminados. De qualquer forma, a equipe sempre seguiu os protocolos necessários, usando máscaras e paramentação necessária para evitar o contágio tanto da equipe quanto dos pacientes.

Na sala de estar e copa da enfermagem, passou-se a restringir o número de funcionários, cuidando para não ter mais que duas pessoas ao mesmo tempo, tirando a máscara somente para alimentação.

Pacientes e familiares são orientados em todos os turnos, quanto ao uso das máscaras. Os acompanhantes passaram a ser permitido somente para as pacientes que vão ganhar o bebê, ou que tenham alguma particularidade, sendo necessário justificar no prontuário a necessidade de permanência do acompanhante, as trocas somente são permitidas uma vez em 24 horas isto no $\mathrm{CO}$ não Covid. Já no $\mathrm{CO}$ Covid, não é permitido a permanência de acompanhante, em algumas situações houve liberação, mas na grande maioria não é permitido.

No pós parto, acompanhantes podem permanecer por 48 horas em casos de parto cesárea e 24 horas em casos de parto vaginal, com exceção de pacientes com deficiências ou distúrbios psiquiátricos que necessitavam de acompanhantes no tempo de permanência no CO.

Das pacientes positivas para Covid 19 para a grande maioria, foi indicado o parto cesáreo no referido $\mathrm{CO}$, as estimativas das taxas de cesarianas entre mulheres infectadas com SARS-CoV-2 diferiram, mas sugerem um aumento potencialmente significativo no parto operatório. Uma revisão sistemática conduzida por Della Gatta et al. (2020) relataram que 90,2\% das mulheres com diagnóstico de COVID-19 por parto cesáreo. Em estudos de janeiro a setembro de 2020, a maioria dos casos de COVID-19 entre grávidas documentados durante a vigilância nos Estados Unidos não progrediu para doença grave, e a admissão à unidade de terapia intensiva (UTI) envolvendo ventilação mecânica raramente foi necessária (DELAHOY, 2020). 


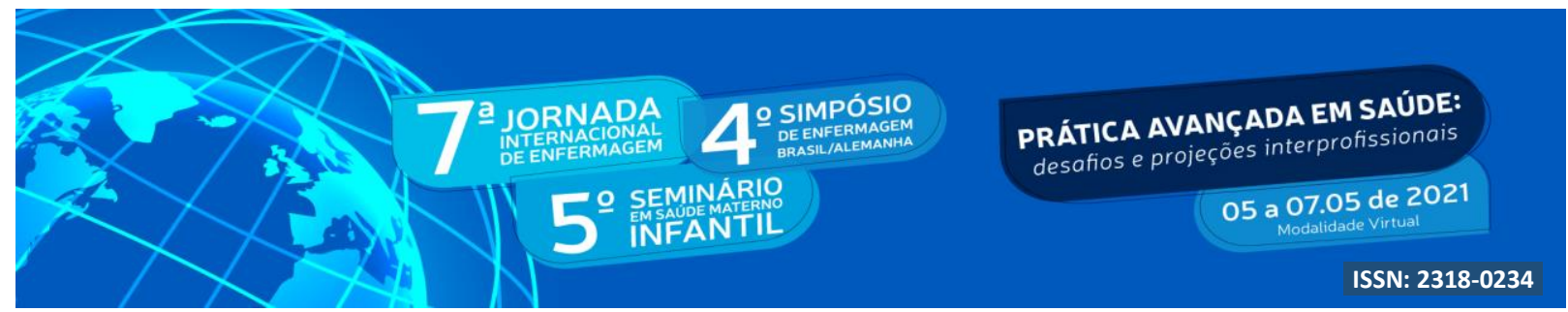

Todos os dias há angústias e medos vividos pelas pacientes e familiares. Quando a internação é para resolução da gestação, nota-se um misto de sentimentos, visto que é uma grande alegria a chegada de um novo membro na família, mas em um momento de muitas dúvidas e acontecimentos em todo o mundo. As pacientes relatam que sentem medo de exposição, tanto delas quanto dos bebês. Klotar et. al. (2021) comentaram sobre vários estudos relacionados a Covid19 na Índia, China e Itália sobre os períodos intraparto e pósparto os quais consideraram a ansiedade e depressão clinicamente relevantes e seus sintomas por meio de autorrelatos e avaliações clínicas.

\section{CONCLUSÃO}

A Covid19 é uma doença extremamente contagiosa causada pelo SARS-CoV-2 e entre indivíduos suscetíveis, ela pode levar a consequências potencialmente fatais. A sua disseminação ocorre com maior frequência em indivíduos sintomáticos ou assintomáticos leves/moderados, que podem transmitir o vírus sem conhecimento.

Devido a pandemia o Centro Obstétrico tem passado por muitos momentos de tensão e preocupação, pois todos os dias há pessoas do convívio e da equipe com resultado positivo para a Covid19. Muito embora os momentos sejam difíceis a equipe precisa enfrentar o momento difícil e desafiador da profissão. O Centro Obstétrico tem o privilégio de ser um setor que simboliza a vida, o nascimento, e o mesmo se tratando de um Centro referência no alto risco de gestante, muitas vezes é necessário atender situações críticas e tristes como a pandemia do novo Coronavírus.

\section{REFERÊNCIAS}

BRASIL. Ministério da Saúde. Quais são os sintomas. Reference: coronavírus - COVID-19. Disponível em: https://coronavirus.saude.gov.br/ [acessado em: 25 março 2021].

DELLA GATTA, A.N., RIZZO, R., PILU, G., SIMONAZZI, G. COVID19 durante a gravidez: uma revisão sistemática de casos relatados. Am J Obst Gynecol. 2020.

DELAHOY, M.J.. Características e resultados maternos e de nascimento de gestantes hospitalizadas com COVID-19 - COVID-NET confirmado em laboratório, 13 estados, 1 de março a 22 de agosto de 2020. Relatório semanal de morbidade e mortalidade. 2020. 


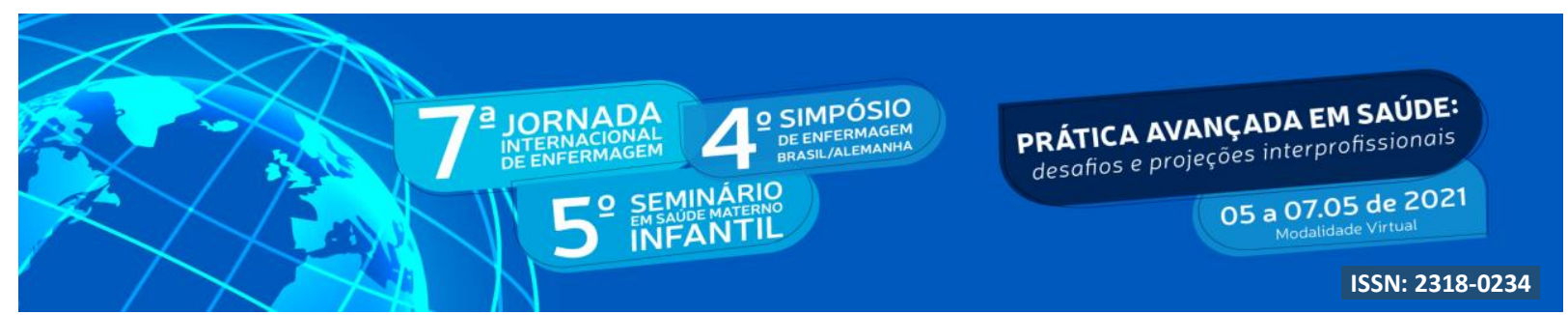

HANTOUSHZADEH et al. Morte materna devido à doença coronavírus 2019. Am J Obstet Gynecol. 2020.

MAO L, JIN H, WANG M, ET AL. Neurologic manifestations of hospitalized patients with coronavirus disease 2019 in Wuhan, China. JAMA Neurol. 2020

KOTLAR, B., GERSON, E., PETRILlO, S., LANGER, A., TIEMEIER, H. O impacto da pandemia COVID-19 na saúde materna e perinatal: uma revisão do escopo. Saúde Reprod. 2021.

ORGANIZAÇÃO PAN AMERICANA DE SAÚDE (OPAS). Folha informativa - COVID19 (doença causada pelo novo coronavírus). 2020. Disponível em:

https://www.paho.org/bra/index.php?option=com_content\&view=articl e\&id=6101:COVID19\&Itemid=875 [acessado em: 27 março 2021].

TAKEMOTO, M.L.S., MENEZES, M.O., ANDREUCCI, C.B., KNOBEL, R., SOUSA, L.A.R., KATZ, L., FONSECA E.B., MAGALHÃES CG, OLIVEIRA, W.K., REZENDEFILHO, J., MELO A.S.O., AMORIM, M.M.R. Mortalidade materna e COVID-19. J Matern Fetal Neonatal Med. 2020.

WORLD HEALTH ORGANIZATION (WHO). WHO coronavirus disease (COVID-19). Reference: situation report - 113. 2020. Disponível em: https://COVID19.who.int/ [acessado em: 24 março 2021].

ZHU, N.A., ZHANG, D., WANG, W., E.T. A.L. A novel coronavirus from patients with pneumonia in China, 2019. N Engl J Med. 2020. 